\title{
Conceptual and experiential estrangement of the self - a neo- Fregean elucidation
}

C W van Staden, MB ChB, MMed (Psych), MD, FTCL, UPLM

Department of Psychiatry, University of Pretoria

Reductionist and non-reductionist philosophers and mental health professionals have debated about what and where the self is. In this article I deploy a neo-Fregean theory to clarify the process by which: (i) the self becomes so susceptible to this debate; and (ii) the self presents so variably in personal experiences. Accordingly, the self can be either estranged or well equipped, depending on the position it occupies in relations, whether in the conceptualisation or in the personal experiences of the self.

What is the self? Where is the self? These have long been vexing questions for mental health practitioners and philosophers alike. In this article I argue that a recent development in the philosophy of Gottlob Frege' is helpful in clarifying the debate between reductionists and non-reductionists on these questions. Although my neo-Fregean theory favours a non-reductionist position, it does not join this debate directly. Rather, it is helpful in clarifying the process by which: (i) the self becomes so susceptible to this debate; and (ii) the self presents so variably in personal experiences. I clarify this process as logically dependent on the ordinary ability of the self to present in a wealth of relations, including relations in which the self is estranged (even extraordinarily) from its properties.

Methodologically, my argument presumes that the approach of the philosopher J L Austin is appropriate here in that clarity is sought through the use of language rather than by attempting yet another definition of the self. ${ }^{2}$ More specifically, my argument explores what is revealed empirically in the use of language concerning what and where the self is. Following Frege, I examine the use of language semantically for this purpose, and I contrast this examination with a syntactic-pragmatic approach to the self.

The need for clarity on the questions what and where the self is, is underscored by the practical need of mental health practitioners who pertinently and perplexedly confront these questions $^{3}$ when examining phenomena such as personal experiences of depersonalisation (e.g. 'I watched my body from a distance'), obsessions (e.g. 'I am obsessed by thoughts about swearing unforgivably at the Holy Spirit'), compulsions le.g. 'These thoughts compel me to check the doors for hours on end'), and delusions of thought insertion (e.g. 'Alien thoughts control and coerce me'l.

Mental health practitioners and philosophers have come up with many answers about what the self would be. ${ }^{4-6}$ Some say the self is the Cartesian ego or the thinking substance, or an incorporeal but essentially conscious person. Some simply identify the self with Plato's concept of soul. ' Reductionist philosophers consider the self a 'mysterious invention' that is better dispensed with altogether, ${ }^{8}$ or claim that the self is 'nothing but' a person, a human being, or a particular description. But non-reductionist philosophers claim the self is something unique and that it is distinguishable from concepts of a person, a human being or a description. 10,11

Reductionists say that the self, being reducible or a mysterious invention, is to be found nowhere. ${ }^{8,9}$ But some non-reductionists claim the self is somewhere elusive. For example, Hume ${ }^{12}$ went on an unsuccessful introspective search: 'For my part, when I enter most intimately into what I call myself, I always stumble on some particular perception or other, or heat or cold, light or shade, love or hatred, pain or pleasure. I can never catch myself at any time without a perception, and never can observe any thing but the perception'. Glover ${ }^{10}$ and McGinn ${ }^{13}$ consider this elusiveness to be a necessary quality of the self. Glover demonstrates it by asking where the 'I' would be in the case of a brain transplant (assuming this was possible).

\section{Neo-Fregean semantic theory and the position(s) of the self}

To ask where the self is, is to ask about the position(s) of the self. The positioning of the self is central to my argument. The semantic theory of Gottlob Frege, which is based on his philosophy of mathematics and the logic of relations, 14,15 was developed to identify semantic positions, irrespective of whether 
occupied by the self or by any other item. According to this theory, which is explicated in detail elsewhere, ${ }^{1}$ sentences are taken to be expressions of relations - relations include actions, states, attitudes and inclinations. Sentences also express the semantic positions inherent in relations, and the occupants of the semantic positions. This may be presented schematically


a relation, the Greek letters $(\alpha$ and $\omega)$ represent the semantic positions inherent in the specific relation, and $A$ and $B$ represent the occupants of the semantic positions.

Two general positions in relations are distinguished. The alpha semantic position is occupied by the owner of that particular relation. The omega semantic position in a relation is occupied by the accidental to that particular relation. These positions are quite easy to identify. For example, say we have a relation, an action in this case, between $x$ and $y$, where $x$ feeds $y$. Whose action is this? The owner of this action is $x$. Therefore, $x$ occupies the alpha position in this relation. Who is the accidental to this action (if no other relations that may bear on this particular action are taken into account)? The accidental to this action is $y$. Therefore, y occupies the omega position. For those relations that are actions, the alpha position is commonly known as the position of the 'agent' and the omega position is commonly known as the position of the 'patient' or 'target'. ${ }^{16}$

The distinction between the semantic positions may seem like a distinction known commonly as that of 'agency'. However, the distinction extends beyond this, for all relations are not actions. Some relations are states or attitudes, for example. For these, the same questions can be asked to identify the semantic positions. For example, when $x$ knows $y$, or $x$ needs $y, x$ is the owner of the knowledge or the need. $x$ occupies the alpha position. The omega position is occupied by the accidental to this knowledge or this need (provided by definition that other relations bearing respectively on these particular states are not taken into account). Similarly, when $x$ is against $y, x$ is the owner of this attitude and $y$ is the accidental to it. $x$ occupies the alpha position and $y$ the omega position.

The distinction between the semantic positions should be mistaken neither for the active-passive distinction nor for the distinction between an internal and an external locus of control, because some relations are respectively not necessarily about actions or not necessarily about control. The active-passive distinction may even be remarkably ambiguous (for example, in the case of passive aggression).

Neither is the distinction between the semantic positions the same as the distinction between subject and object positions, or the order in which they are expressed. For example, in 'John is the neighbour of Mary', John and Mary are the subject and the object respectively. But both John and Mary occupy the alpha position in this symmetrical relation, for both are owners of the neighbourship.

These semantic positions should not be mistaken for grammatical or syntactical positions but exist independently of whether they are expressed in verbal or written language. For example, 'John stroked the dog' is the verbal or written expression of a particular relation that pertained between John and the dog. This action happened irrespective of whether it was expressed in verbal or written language. John occupied the alpha position in this relation ('stroking') irrespective of whether this was expressed. Further, even if this action was verbalised, languages may have more than one way to express the same semantic position. For example, John and the dog still occupy the alpha and the omega positions respectively when the relation used in the above example is expressed by 'the dog was stroked by John'.

The semantic positions and relations are thus distinguished from the expressions of semantic positions and relations. Moreover, true to Fregean philosophy, relations and their semantic positions are taken to be logically primary over expressions thereof. This means that sentences are seen to be a mirror of relations, semantic positions and their occupants. Viewing sentences in this way contrasts with syntax theory, in which grammatical expressions are considered to be the foundations of meaning. ${ }^{17,18}$ It also contrasts with pragmatic theory, which focuses on the symbolic value and purposes behind expressions. ${ }^{19,20}$

These distinctions are pertinent to considerations relating to the position of the self. The neo-Fregean philosophy unravels the positioning and conceptualisation of the self /whether in philosophical debate or in personal experiences) by examining the presentation of the self in verbal or written sentences where sentences are a mirror in which can be seen the relations and semantic positions occupied by the self. Accordingly, occupancy of the semantic positions by the self is expressed by first-person pronouns (these are I, me, we, us, etc.) in many languages, notwithstanding other ways in a classical language like Latin. But while the first-person pronouns indicate - which is Frege's choice of word for the role of pronouns - the self, they are not the self.

Distinct from the neo-Fregean theory, the philosophical pragmatists 
Mead and Peirce attached symbolic purposes to the specific syntactically defined declensions of first-person pronouns, saying ' $I$ ' always symbolises the 'present self' and 'me' always symbolises the 'past self'. 19,20 Similarly, psychoanalytic theorists have mostly followed the pragmatic tradition by considering the functions and purposes of using first-person pronouns. 5,21-23

\section{The self can be conceptualised and experienced variably}

\section{What is the self - from something estranged to something equipped}

Having described the positioning of the self in neo-Fregean terms, I will now show how the positioning of the self and its properties account for the variable ways of conceptualising and experiencing the self. The variable ways of conceptualising and experiencing the self have to do with: (i) the self, as expressed by the use of first-person pronouns, which is able to present in a wealth of (variable) relations and in distinct semantic positions; and (ii) the self that is able to stand in a relationship with its properties. For example, when I wash my hands, I (the self) occupy the alpha position and my hands (properties of self) occupy the omega position in this relation of washing. The self can therefore occupy a position different from the position simultaneously occupied by its properties. Applied simplistically to this example, this approach implies that in this relation I am here but my hands are there.

As if it were not strange enough, the estrangement between the self and its properties is especially vivid in cases of opposing and distancing relations. For example, in 'I hate my emotions, thoughts, and disgusting body' an opposing relation pertains between the self in one position (alpha) and its emotions, thoughts and body in another position (omega), as if the thoughts, emotions and body do not quite belong to the self. The same appears to be true for the depersonalisation experiences 'I $(\alpha)$ watched my body $(\omega)$ from a distance' and 'I $(\alpha)$ parted from my body $(\omega)^{\prime}$; for obsessive-compulsive experiences 'I ( $\omega)$ am obsessed by thoughts $(\alpha)$ that require me $(\omega)$ to swear' and 'these thoughts $(\alpha)$ compel me $(\omega)$ to check the doors for hours on end'; and for thought insertion delusions 'alien thoughts $(\alpha)$ control and coerce me $(\omega)^{\prime}$ '.

If these opposing and distancing relations between the self and its properties are sufficiently dominant, the self may become significantly estranged from its properties. This happens in clinical practice and in philosophy. For example, the patient suffering from borderline personality disorder often feels that 'I hate everything about me'. The philosopher Descartes, in turn, proclaimed 'I shall consider myself as having no hands, no eyes ...' ${ }^{24}$
Estrangement of this order would inevitably result in an impoverished self, whether in its conceptualisation or in personal experiences. If the self were to become estranged from all its properties, if this were possible, the self would be very elusive if it existed at all. The same applies analogously to a car stripped of all its properties - where would the car be?

Notwithstanding the ability of the self to become impoverished through a process of estrangement, the neo-Fregean elucidation of the self also reveals the opposite possibility. That is, a potentially rich conceptualisation and experience of the self. Accordingly, the self is necessarily equipped to occupy a particular semantic position in a relation. For example, when 'I kick the ball through the goal posts', it is neither merely a Cartesian ego, an incorporeal person, a soul, nor a 'mysterious invention' that kicks the ball. No, the self is equipped with a leg able to kick, and equipped with consciousness and the capacity to kick the ball intentionally. Similarly, 'Mary hurts me' only if I have emotions to experience the hurt. 'I am thinking about a holiday' only if I have thoughts to do so.

Thus, this neo-Fregean theory holds a rich conceptualisation of the self, for we ordinarily occupy semantic positions in a great variety and wealth of relations for which we are necessarily equipped simply by virtue of our occupying these positions.

However, if properties of the self are lost or inadequate or sufficiently estranged, the self cannot occupy positions in those relations for which the lost or inadequate properties would have been necessary. For example, if I lost my legs, I cannot kick the ball. Similarly, where properties are lost or inadequate or sufficiently estranged as part of psychopathology, some incapacity or impairment in functioning is to be expected. Small wonder, then, that incapacity or impairment in functioning features so prominently in conceptualisations of mental disorder, in philosophy ${ }^{25-27}$ and in diagnostic practice (DSM-IV28 requires for most of the disorders that functioning be impaired significantly).

Estrangement of the self from its properties features in several psychopathological experiences. Dixon, ${ }^{29}$ who developed the first measuring instrument for depersonalisation, observed the distancing between the self and 'parts of me' in depersonalisation experiences, and subsequently identified an 'alienation' cluster of items in this measure of depersonalisation. In dissociative identity disorder, the estrangement of opposing and contending identities or personalities or 'parts of me' is a common feature. Furthermore, probably the most extreme estrangement between the self and its properties is seen in thought insertion experiences in which the self is so estranged from its thinking that its thinking is attributed to someone else. 
Thought insertion, being an extreme example of estrangement between the self and its thoughts, is a phenomenon that has critical bearing in philosophy on the so-called adhesiveness between 'I' and 'my thoughts'. Descartes' cogito ergo sum insisted on this adhesiveness, and in contemporary philosophy the adhesiveness of ' $I$ ' is claimed to be an 'immunity to error through misidentification'. ${ }^{30,31}$ Some authors ${ }^{32,33}$ took issue with this claim by arguing that the pathological phenomenon of thought insertion breaks up the adhesion. This neo-Fregean elucidation of the estrangement process offers an account of how the adhesiveness between ' $I$ ' and 'my thoughts' could be undermined. It is the possibility of occupying simultaneously different semantic positions in the same relation that allows for the adhesiveness to be undermined, for 'I' might occupy one semantic position and '(my) thoughts' another.

For the therapeutic situation, it is critical not to assume that an estrangement between the self and some of its properties would necessarily be unhealthy, bad, or untherapeutic. Rather, a judgement as to whether a particular incident of estrangement of the self would be healthy or unhealthy, good or bad, therapeutic or untherapeutic would require far more sophistication than the mere identification and description of the estrangement process. Such a judgement could nonetheless be useful in the therapeutic situation.

\section{Where is the self - from nowhere to a precise position}

In reductionist conceptualisations, the self would be located nowhere (as envisaged by Anscombe and Parfit) if the self were completely estranged from its properties. If not completely estranged, the self would be somewhere elusive as it is elusive in Hume's perceptions, Descartes' cogito, or Plato's 'soul'. Contrastingly, this neo-Fregean theory locates the self in the semantic positions of relations. Accordingly, the positions of the self in relations are mirrored by first-person pronouns in sentences.

Similarly, in psychopathology and psychotherapy the self occupies the semantic positions in the relations with its properties, people, the clinician, concrete and abstract things, and anything conceivable. The clinician can identify the positions of the self by paying attention to the patient's use of first-person pronouns in sentences, which could be useful therapeutically. ${ }^{34,35}$ For example, such identification of the location of the self could be utilised in a psychodynamic understanding whereby the (estranged) position of the self may be made explicit in an interpretation. The cognitive-behavioural therapist, for example, could identify the location of the self in unwanted positions in relations and then prescribe occupancy of desired positions.

\section{Conclusion}

A recent development in the philosophy of Gottlob Frege sheds new light on the questions as to where and what the self is. It locates the self empirically in the semantic positions of relations, where the positions of the self in relations are mirrored by first-person pronouns in sentences. Accordingly, the self ordinarily occupies semantic positions in a great variety and wealth of relations in which the self can occupy a position in a particular relation only when sufficiently equipped to do so. This is a rich presentation of the self, whether in the way it is conceptualised (e.g. in philosophy or in psychological theoryl or in personal experiences (e.g. in psychotherapy).

The neo-Fregean philosophy also clarifies the location of an impoverished self. An impoverished self would therefore be nowhere or somewhere elusive and perhaps even non-existent when it is (sufficiently) estranged from its properties, whether in reductionistic conceptualisations of the self or in personal experiences.

\section{References}

1. Van Staden CW. Linguistic markers of recovery: theoretical underpinnings of firs person pronoun usage and semantic positions of patients. Philosophy, Psychiatry, Psychology 2002a; 9: 105-126.

2. Urmson JO, Warnock GJ, eds. JL Austin: Philosophical Papers. Oxford: Clarendon Press, 1979.

3. Radden J. Divided Minds and Successive Selves: Ethical Issues in Disorders of Identity and Personality. Cambridge, Mass: MIT Press, 1996.

4. Cassam Q, ed. Self-knowledge. Oxford: Oxford University Press, 1994

5. De Waele M. A clinical concept of self: the experiential being. Br J Med Psychol 1995; 68: 223-242

6. Harré R. Personal Being. Oxford: Blackwell, 1983: 26

7. Flew A. A Dictionary of Philosophy. London: Pan Books, 1984

8. Anscombe GEM. The first-person. In: Cassam Q, ed. Self-knowledge. Oxford Oxford University Press, 1994

9. Parfit D. Reasons and Persons. Oxford: Clarendon Press, 1984

10. Glover J. 'I': The Philosophy and Psychology of Personal Identity. London: Penguin Press, 1988.

11. Nagel T. The View from Nowhere. Oxford: Oxford University Press, 1986.

12. Hume D. A Tretise of Human Nature. Selby-Bigge LA, Nidditch PH, eds. Oxford: Clarendon Press, 1978.

13. McGinn C. The Subjective View: Secondary Qualities and Indexical Thoughts. Oxford: Clarendon Press, 1983

14. Frege G. Translations from the Philosophical Writings of Gottlob Frege. Geach P, Black M, transl. Oxford: Basil Blackwell, 1966

15. Lemmon EJ. Beginning Logic. 2nd ed. London: Chapman and Hall Medical, 1996.

16. Brown K. Linguistics Today. Suffolk: Fontana, 1984

17. Van Staden CW. Language mirrors relational positions in recovery: a response to commentaries by Falzer and Davidson, Gillett, and Suppes. Philosophy, Psychiatry, Psychology 2002b; 9: 137-140.

18. Chomsky N. Aspects of the Theory of Syntax. Cambridge, Mass: MIT Press, 1965.

19. Mead GH. Mind, Self, and Society. London: The University of Chicago Press, 1967.

20. Wiley N. The Semiotic Self. Padstow, England: Polity Press, 1994

21. Rizzuto A. First person personal pronouns and their psychic referents. IntJ Psychoanal 1993; 74: 535-546.

22. Lacan $\rfloor$. The mirror stage as formative of the function of the I. In: Sheridan A, transt. Écrits. London: Tavistock Publications, 1977: 1-7.

23. Hinshelwood RD. A Dictionary of Kleinian Thought. London: Free Association Books, 1991: 284-285, 425.

24. Haldane ES, Ross GRT. The Philosophical Works of Descartes. Cambridge: 
Cambridge University Press, 1973

25. Fulford KWM. Moral Theory and Medical Practice. Cambridge: Cambridge University Press, 1989

26. Van Staden $\mathrm{CW}$, Krüger $\mathrm{C}$. Incapacity to give informed consent owing to mental disorder. J Med Ethics 2003: 29: $41-43$.

27. Nordenfelt L. Mild mania and a theory of health: a response to 'mild mania and well-being'. Philosophy, Psychiatry, Psychology 1994, 1: 179-184.

28. American Psychiatric Association. Diagnostic and Statistical Manual of Mental Disorders (DSM-IV). 4th ed. Washington, DC: APA, 1994.

29. Dixon JC. Depersonalisation phenomena in a sample population of college students. BrJ Psychiatry 1963; 109: 371-375

30. Evans $G$. The Varieties of Reference. McDowell J, ed. Oxford: Clarendon Press, 1982
31. Wittgenstein L. The Blue and Brown Books. Oxford: Basil Blackwell, 1958: 66-68.

2. Fulford KWM. Thought insertion, insight and Descartes' cogito: linguistic analysis and the descriptive psychopathology of schizophrenic thought disorder. In: Sims A ed. Speech and Language Disorders in Psychiatry: Proceedings of the Fifth Leeds Psychopathology Symposium. London: Gaskell, 1995.

33. Stephens GL Graham G Self-consciousness, mental agency and the clinical psychopathology of thought insertion. Philosophy, Psychiatry, Psychology 1994; 1 $1-10$.

34. Van Staden CW, Fulford KWM. Changes in semantic uses of first person pronouns as possible linguistic markers of recovery in psychotherapy. Aust N Z J Psychiatry 2004 38: 226-232.

35. Gillett $G$. The self as relatum in life and language. Philosophy, Psychiatry, Psychology 2002; 9: $127-130$.



